\title{
THREE CASES OF UNUSUAL PRESENTATION OF FIBROID
}

\author{
Moulika Shah'1, Manisha Laddad²
}

${ }_{1}^{1}$ Postgraduate Student, Department of Obstetrics and Gynaecology, Krishna Institute of Medical Sciences, Karad, Maharashtra, India. ${ }^{2}$ Associate Professor, Department of Obstetrics and Gynaecology, Krishna Institute of Medical Sciences, Karad, Maharashtra, India.

HOW TO CITE THIS ARTICLE: Shah M, Laddad M. Three cases of unusual presentation of fibroid. J. Evolution Med. Dent. Sci. 2018;7(35):3926-3928, DOI: 10.14260/jemds/2018/878

\section{PRESENTATION OF CASE}

Fibroid is the most common solid, hypoechoic mass in pelvic region which we see on ultrasonography in reproductive age group, because almost $25 \%$ patients are asymptomatic. Fibroid is the common benign condition arising from smooth muscle cells.(1) When the tumour fills the whole pelvis or is pedunculated, there is always an uncertainty regarding the uterine or ovarian origin of the tumour. A cervical fibroid, especially with degenerative changes mimics an ovarian tumour and causes a clinical dilemma.(2)

Fibroid is easy to diagnose and manage, but here we report successful management of cases of perimenopausal women with unusual finding of fibroid. Provisional diagnosis on basis of imaging and on per vaginal examination was showing uterine fibroid. Patients were posted for abdominal panhysterectomy. Such cases are exemplified for its rarity and diagnostic difficulty.

\section{CLINICAL DIAGNOSIS}

1. A 42-year perimenopausal patient presented to our gynaecology outpatient department with complaints of lower abdominal pain and backache with heaviness in abdomen. Patient took medication from local practitioners for symptomatic relief. Patient was para three with three live issues, younger child of 18-year-old delivered by normal vaginal delivery. Menarche was attained at age of 13 years. Patient had regular menstrual cycles occurring at every 28 - 30 days with bleeding lasting for $4-5$ days. The amount of blood flow is normal, but since 5 months patient has amenorrhea. UPT was done on admission, which turn out be negative. There was no previous illness or surgical intervention, except for patient underwent tubal ligation about 18 years ago. Patient was non-vegetarian, non-smoker, nonalcoholic with normal bowel habits. She was well nourished. General condition of patient was stable with mild pallor. Vitals were normal. Abdominal examination revealed nothing significant. Pelvic Examination: Per speculum examination- cervix and vagina healthy. Per vaginal examination, uterus was bulky with anteverted. Solid mass of about 8 to $10 \mathrm{~cm}$ irregular, firm in consistency felt in left fornix. Baseline investigations were normal. Ultrasonography revealed hypoechoic, solid mass measures $8 \mathrm{~cm} \times 4 \mathrm{~cm} \mathrm{x} 4 \mathrm{~cm}$ in size. CA-125 was $5 \mathrm{mIU} / \mathrm{mL}$. Mass is seen in pelvis on the left side suggestive of

'Financial or Other Competing Interest': None.

Submission 07-07-2018, Peer Review 10-08-2018,

Acceptance 16-08-2018, Published 27-08-2018.

Corresponding Author:

Dr. Moulika Shah,

170/Sadashiv, Peth, Satara,

Maharashtra, India.

E-mail: moulikashah@gmail.com

DOI: $10.14260 /$ jemds $/ 2018 / 878$ pedunculated fibroid with degeneration. Considering the above clinical findings and investigations, provisional diagnosis of degenerated fibroid was made and abdominal hysterectomy planned.

2. A 40-year perimenopausal patient presented to our gynaecology outpatient department with complaints of abdominal pain and per vaginal spotting with 4 months amenorrhea. UPT was done which was negative. Patient was para three with three live issues, younger child of 12-year-old delivered by normal vaginal delivery. Menarche was attained at the age of 13 years. Patient had regular menstrual cycles occurring at every $28-30$ days with bleeding lasting for $1-2$ days. The amount of blood flow was normal, but since 4 months patient has amenorrhea. There was no previous illness or surgical intervention, except for patient underwent tubal ligation about 11 years ago. Patient was non-vegetarian, nonsmoker, non-alcoholic with normal bowel habits. She was moderately built and nourished. General condition of patient was stable with mild pallor. Vitals were normal. Abdominal examination revealed uterus of 18 weeks size, mobility restricted. On per speculum examination, cervix was not visualised. Mass was visualised in vagina about $6 \times 6 \mathrm{~cm}$. Per vaginal examination, os was opening on right side? cervical fibroid. Baseline investigations were normal. Ultrasonography revealed grossly uterus, bulky, measuring $18 \mathrm{~cm} \times 12 \mathrm{~cm} \times 12 \mathrm{~cm}$. Large fibroid $13 \mathrm{~cm} \times$ $10 \mathrm{~cm} \times 10 \mathrm{~cm}$, volume $780 \mathrm{cc}$, occupying entire uterus and sparing cervix. Considering the above clinical findings and investigations, provisional diagnosis of uterine fibroid was made and abdominal hysterectomy planned.

3. A 42-year perimenopausal patient presented to our gynaecology outpatient department with complaints of lower abdominal pelvic pain and difficulty in voiding with increased frequency in urination. Patient was para two with two live issues, younger child of 22-year-old, delivered by normal vaginal delivery. Patient had regular menstrual cycles occurring at every 28 - 30 days with bleeding lasting for $2-3$ days. The amount of blood flow was normal and patient's last menstrual period was 8 days back. Patient was a known case of hypertension, on treatment. Patient underwent tubal ligation about 18 years ago. Patient was vegetarian, non-smoker, nonalcoholic with normal bowel habits. She was moderately built and nourished. General condition of patient was stable with severe pallor. Vitals were normal. Abdominal examination revealed uterus of 18 weeks size. Scar of tubal ligation present. On per speculum examination, cervix was not able to visualise. Brownish discharge was present. Per vaginal examination, uterus was 18 weeks size. Irregular posterior surface? something coming out of cervix. Baseline investigations were normal. 
Ultrasonography revealed uterus of $5 \mathrm{~cm} \times 4 \mathrm{~cm} \times 5 \mathrm{~cm}$ in size. Cervix bulky, a large iso-hyperechoic, solid mass measures $10 \mathrm{~cm} \times 8 \mathrm{~cm} \times 10 \mathrm{~cm}$ in size. Considering the above clinical findings and investigations, provisional diagnosis of cervical fibroid was made and abdominal hysterectomy planned.

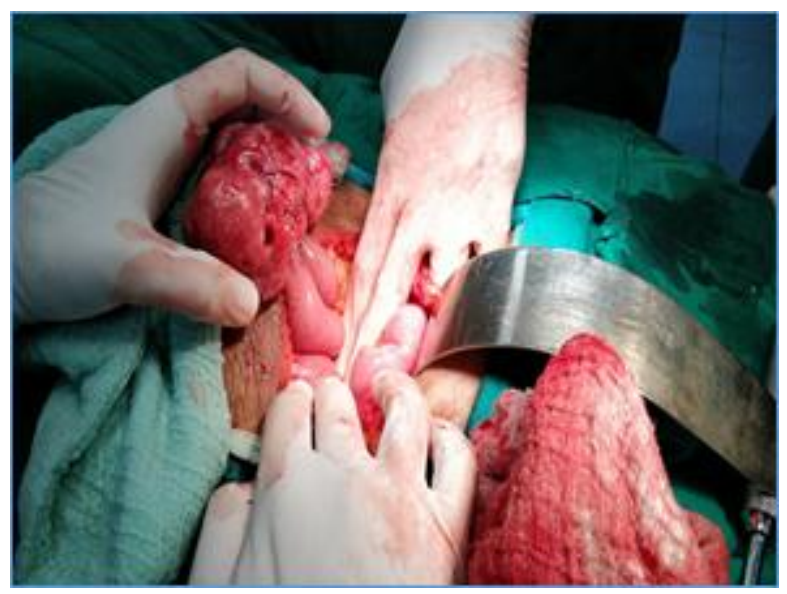

Case 1

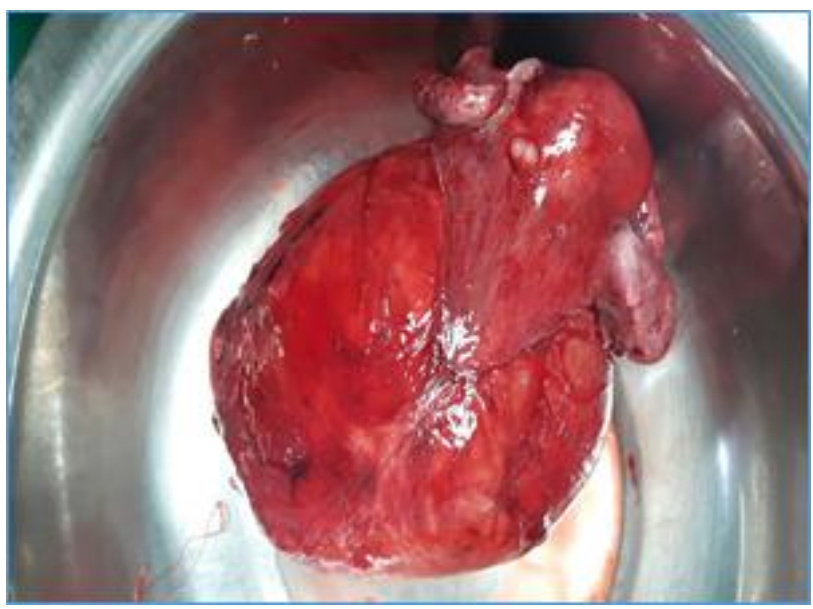

Case 2

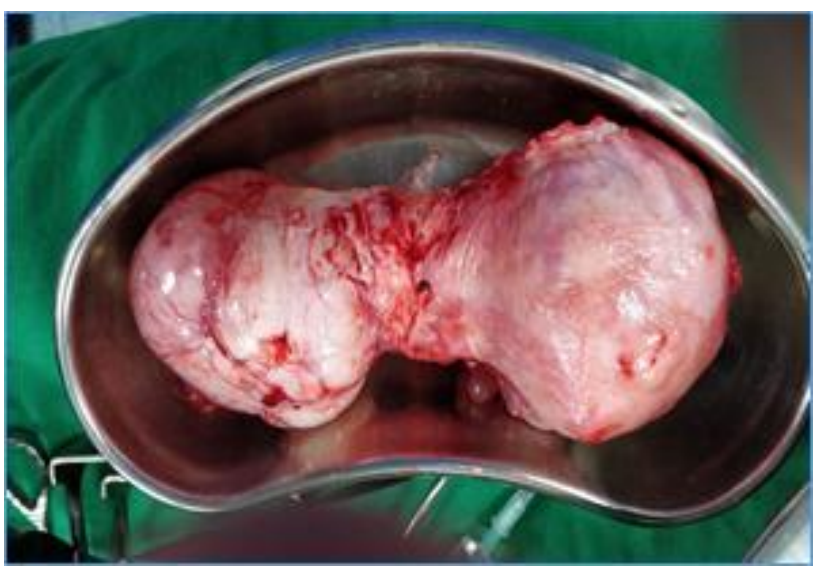

Case 3

\section{DISCUSSION OF MANAGEMENT}

Intraoperatively, in case first uterus was found to be just normal in size with bilateral tubes and ovary normal in size, a large jejunal wall mass about $8 \mathrm{~cm}-6 \mathrm{~cm}-6 \mathrm{~cm}$ with nodular surface was seen. So procedure of abdominal hysterectomy was abandoned and on call surgeon was asked to intervene and only excision of large jejunal wall mass was done followed by jejunal anastomosis. Jejunal masses were sent for histopathological examination. On histopathological examination, it turns out to be GISTs. Imatinib, which is chemotherapeutic drug was started as neoadjuvant.

In second case, intraoperatively uterus was found to be bulky with bilateral tubes and ovary was normal in size with large cervical fibroid of $18 \mathrm{~cm} \times 15 \mathrm{~cm} \times 10 \mathrm{~cm}$. So the procedure proceeded to abdominal panhysterectomy. Histopathology revealed the same.

In third case intraoperatively, uterine fibroid of $8 \mathrm{~cm}-$ $8 \mathrm{~cm}-8 \mathrm{~cm}$ with bilateral tubes and ovary normal in size, and cervical fibroid of $6 \mathrm{~cm} \times 5 \mathrm{~cm} \times 6 \mathrm{~cm}$. So the procedure proceeded to abdominal panhysterectomy. Histopathology revealed the same.

\section{FINAL DIAGNOSIS}

Fibroids are benign smooth muscle tumours of uterus. Although, cervical polyps can be seen at any age, they occur most frequently in multiparous women in their fifth decade of life. These are considered to be oestrogen and progesterone dependent. They can distort the uterine cavity. Anterior fibroids may present with urinary symptoms, posterior may present with difficulty passing stools, lateral would extend to broad ligament and central fibroid pushes the uterus upwards.(3) These fibroids push the bladder up. Ureters are pushed laterally and uterine vessels are also pushed up and laterally making these structures more prone to injury during surgery.(4) USG is the initial investigation done for the diagnosis of fibroid. Both transvaginal and transabdominal USG can be done. Fibroids appear as well-defined, solid masses with a whorled appearance. These are usually of similar echogenicity to the myometrium, but sometimes may be hypoechoic. MRI is the preferred method for accurately characterising pelvic masses. It has been shown to be more sensitive in identifying uterine fibroids than USG.(5) Submucosal, intramural and subserosal fibroids are usually easily differentiated with MRI and fibroids as small as $5 \mathrm{~mm}$ in diameter can be demonstrated. Fibroids in relatively unusual locations such as within the cervix can also be identified. Treatment of cervical fibroid is either hysterectomy or myomectomy. They may give rise to greater surgical difficulty by virtue of relative inaccessibility and close proximity to bladder and ureter. Preoperative evaluation helps in deciding the route and procedure of choice.(6)

After treating successfully, we came to conclusion that uterine fibroids are common even in perimenopausal women. They present with varied manifestations posing difficulties in diagnosis and management. Thorough preoperative evaluation and anticipating operative challenges and judicious treatment help in relieving the misery of the patient.

\section{REFERENCES}

[1] Jones HW, Rock JA. Leiomyomata uteri and myomectomy. Te Linde's Operative Gynaecology. $10^{\text {th }}$ edn. Philadelphia, PA, USA: Lippincott Williams and Wilkins 2008: p. 687-96.

[2] Basnet N, Banerjee B, Badani U, et al. An unusual presentation of huge cervical fibroid. Kathmandu Univ Med J (KUMJ) 2005;3(2):173-4. 
[3] Nanda S, Sangwan K, Gulati N. Giant cervical polyp. Trop Doct 1998;28(2):112-3.

[4] Kshirsagar SN, Laddad MM. Unusual presentation of cervical fibroid: two case reports. International Journal of Gynae Plastic Surgery 2011;3(1):38-9.

[5] Wilde S, Scott-Barrett S. Radiological appearances of uterine fibroids. Indian J Radiol Imaging 2009;19(3):222-31.
[6] Monaghan JM, Lopes AB, Naik R. Total hysterectomy for cervical and broad ligament fibroids. In: Huxley R, Taylor S, Chandler K, eds. Bonney's gynaecological surgery. 10th edn. Blackwell Publishing 2004: p. 74-86. 